\title{
DOCUMENTOS
}

\section{Discurso de toma de posesión como Director de INSA-ETEA}

El día 3 de junio pasado tomaba posesión como Director de INSA-ETEA D. Gabriel $M^{a}$ Pérez Alcalá, Profesor Titular de Política Económica en nuestra Facultad de Ciencias Económicas y Empresariales, institución a la que pertenece desde 1987.

En nuestras páginas no solemos publicar cosas relativas a la vida interior de la institución en que la RFS se publica. Pero en esta ocasión el Consejo de Redacción ha considerado oportuno dar a conocer a nuestros lectores este texto. Es cierto que tiene un carácter algo circunstancial, como se ve por algunas alusiones concretas que hay en él. Es más, hemos preferido respetar el texto tal como se pronunció y reproducirlo completo sin omitir esas alusiones. Pero no es un discurso sólo coyuntural: en él se sintetiza bien lo que INSA-ETEA quiere ser como centro universitario de la Compañía de Jesús. Nuestros lectores encontrarán en él un perfil de lo que es la matriz desde donde nace la RFS: esperamos, por tanto, que estas páginas les ayuden a conocer mejor los rasgos distintivos de la identidad de nuestra revista.

Señor vicerrector de la Universidad de Córdoba, Señor Rector Magnífico de la Universidad Fernando III, Reverendo Padre Provincial de la Compañía de Jesús, Señor presidente de INSA-ETEA, Señor director de la Facultad de Ciencias Empresariales, estimadas autoridades eclesiásticas, académicas y civiles, compañeros y compañeras del claustro y del personal de ETEA, queridos amigos y amigas.

\section{Introducción. Agradecimientos, prolegómenos}

Permítanme que como persona que se tiene por bien nacida empiece estas palabras con unas de agradecimiento. 
En primer lugar, quiero expresar mi más sentido agradecimiento a Jesús Ramírez, y a las personas que han encarnado lo que en esta Casa conocemos como el equipo directivo, por estos nueve años de servicios y desvelos en el desempeño de las responsabilidades que ahora asumo. Gracias, querido Jesús, por tu dedicación, por tu esfuerzo y por tu disponibilidad. Gracias, también, por algunas de esas canas que reflejan las muchas preocupaciones que sé que has tenido. De corazón, para ti y aquellos que más directamente lo han compartido contigo, gracias.

En segundo lugar, me gustaría dejar constancia de mi agradecimiento a la Compañía de Jesús por el alto honor que me hace al confiarme la dirección de ETEA. Soy consciente de la importancia de esta obra apostólica en el contexto de la Provincia Bética, del peso de su historia y de sus posibilidades de futuro, y, por ello, soy consciente de la muestra de bondad que supone ofrecerme este servicio.

Finalmente, quiero agradecer a todos ustedes su presencia esta tarde, por todo lo que significa de aprecio a nuestra Institución y de apoyo a mi persona, en este acto de apertura de una nueva etapa de esta que también es su Casa.

Mi discurso será breve. Porque una pieza oratoria de esta naturaleza tiene, al menos en mi opinión, un parte de credo y otra de arenga.

Una primera parte de credo, de recordatorio de nuestra historia, de acto de fe en lo que somos, de recitativo de nuestra esencia, que, aunque a alguno le suene, como buen creyente, a un conjunto de obviedades, es siempre conveniente decir para no olvidarla.

La otra parte es de arenga. Una arenga en la que sólo hay que esbozar la misión a cumplir y el rumbo que tiene que seguir la nave que sale a la mar. En este caso, la dirección en la que navegaremos hacia el futuro.

Así pues, permítanme que el discurso sea la suma de dos partes: un acto de fe en lo que es ETEA, una arenga sobre lo que debemos hacer en la navegación que ahora iniciamos. 


\section{Nuestra historia como exigencia}

ETEA, así la definimos en todos nuestros documentos, es una Institución Universitaria de la Compañía de Jesús, adscrita a la Universidad de Córdoba.

En nuestra Declaración Institucional, aprobada en agosto del 2000, se puede leer en su párrafo tercero: "En cuanto a Institución Apostólica de la Compañía de Jesús, ETEA fue creada y es mantenida como instrumento para su misión: el servicio de la fe y la promoción de la justicia en un mundo de diversidad cultural y religiosa. Para realizar esta misión, y siguiendo la tradición universitaria de la Compañía de Jesús, ETEA se constituye como una institución universitaria inserta en el entorno andaluz."

Dicho de otra forma, nuestra esencia es la de ser un centro universitario, nuestra característica es el serlo de la Compañía de Jesús.

Universidad. Hermosa palabra que expresa la vocación, para lo que ha sido llamada ETEA y cuantos somos parte de ella. ETEA fue en su origen y sigue hoy siendo, cuarenta y cinco años después, un centro universitario. $Y$ como centro universitario tiene la obligación primigenia de ser lugar de "creación de pensamiento libre y crítico", como recogía la vieja LRU, que nosotros completamos considerándonos como un lugar "de serena y abierta investigación y discusión de la verdad en el que se garanticen la autonomía fundamental, la integridad y la sinceridad" (Declaración institucional, 6).

ETEA es y pretende ser permanentemente un lugar de pensamiento, de conocimiento, de diálogo.

Un pensamiento que se transmite a las generaciones más jóvenes a través de la docencia, un pensamiento que se brinda a todos a través de las publicaciones, un pensamiento que se comparte en las colaboraciones con todo tipo de instituciones y en todos los foros. Tenemos, pues, una cuádruple tarea: pensar e investigar, formar a los jóvenes, publicar, colaborar con todos. Esto es lo que hacemos, esto es lo que hemos de hacer, porque como Institución "para esto fuimos creados".

Fuimos creados para enseñar, para que haciéndolo, nuestros alumnos y alumnas aprendan a ser. A ser hombres y mujeres para los demás, agentes de cambio hacia un mundo más justo, más solidario, más humano. Hombres y mujeres buenos que estén preocupados por los demás, que tengan un deseo constante de aprender y de mejorar, que sean sensibles a los más desfavorecidos, que tengan sentido 
crítico, que sean respetuosos y tolerantes, que tengan aprecio por la excelencia académica, entendida ésta no en un sentido competitivo, sino como una continua superación de sí mismos.

Como nos recordó el Padre Kolvenbach en su visita de 1994: "No es una institución verdaderamente universitaria la que produce profesionales conformistas que se contentan con cualquier cosa, sino la que infunde a sus alumnos y alumnas un estimulante afán de calidad y excelencia".

Las más de 1.800 personas que componen nuestro alumnado actual, los más de 8.000 antiguos alumnos y alumnas, más de 4.000 en extensión universitaria, miles en los cursos que damos por todo el mundo, pueden certificar que esta es nuestra vocación, aunque, como obra hecha por seres humanos, no siempre lo hagamos bien, porque somos, a veces, imperfectos.

Y junto a la enseñanza, ETEA fue creada para investigar. "Porque nada menos universitario que una transmisión repetitiva de conocimientos que es pura memoria del pasado, carente de sentido innovador y crítico". ETEA es un lugar orientado a la investigación. Una clara orientación investigadora interdisciplinar y multidisciplinar que nos ha hecho un centro de referencia en algunas áreas. De nuestros equipos, integrados también por personas de centros cercanos a nosotros como la Escuela Técnica Superior de Ingenieros Agrónomos y de Montes, han salido, desde hace más de cuarenta años, investigaciones sobre la economía agraria, la teoría y práctica del desarrollo rural, estudios de empresa, responsabilidad social, trabajos sobre financiación, sobre economía regional, sobre empresas cooperativas, sobre la integración económica. Más de cincuenta investigadores mantienen hoy viva la llama de la búsqueda de la verdad en distintos campos de las ciencias sociales y jurídicas, perseverando en nuestra larga y fructífera tradición.

ETEA, además, colabora con los demás en tres ámbitos que son esenciales para su propia esencia de centro universitario dedicado a las ciencias sociales.

Porque como centro de formación de líderes para la empresa mantiene una estrecha colaboración, con la ayuda impagable de los antiguos alumnos, con cientos de empresas, con las organizaciones empresariales, con las instituciones empresariales. No hay empresa o institución de una cierta importancia en nuestra provincia que no tenga en su plantilla personas formadas en nuestras aulas. Quizás no lo hemos hecho todo tan bien como nos hubiera gustado en el fomento de la iniciativa empresarial, y eso que la Asociación de Jóvenes Empresarios de Córdoba se fundó en nuestras aulas, pero no es menos cierto que hemos sido pioneros en 
los campos de las prácticas de empresa, de la misma forma que fuimos el tercer centro de España, tras nuestros hermanos de ICADE y ESADE, en tener una Bolsa de Trabajo.

ETEA, además, es un centro universitario en red con otros centros universitarios. Así, desde antes de que existiera el sistema Erasmus, nuestro alumnado tenía experiencias de intercambio internacional. Alguno hubo que hizo prácticas de verano en "kibbutzs" israelíes y no pocos tuvieron estancias en Francia o Alemania, incluso en Argelia. Hoy el alumnado de otras nacionalidades, y no sólo europeas, sino americanos y asiáticos es una realidad en nuestro campus. Más de 70 personas de distintos países y continentes reciben clases en nuestras aulas. Incluso estamos haciendo el esfuerzo de ofrecer clases en inglés en todas las asignaturas de los cursos superiores. Y muchos de los miembros del claustro tenemos una amplia experiencia como profesores en universidades extranjeras.

Pero, además de con el entorno empresarial, académico y administrativo más cercano, ETEA coopera solidariamente con el entorno empresarial, institucional y académico más lejano, en especial, con aquel que radica en lugares donde la pobreza es una realidad cierta. ETEA coopera, desde luego que hace cooperación. $Y$, como en otras actividades, también en esto fuimos de los primeros en empezar la cooperación universitaria, allá por finales de los ochenta. Hoy ETEA tiene una fundación nacida de ella que canaliza este esfuerzo, en la que trabajan más de quince personas con presencia en toda Centroamérica, en Vietnam, en Camboya, en Ecuador, en Venezuela, haciendo no sólo trabajos de campo, sino asesoría del más alto nivel en instituciones internacionales para el desarrollo y la integración. Personal de ETEA y antiguos alumnos trabajan y colaboran con el Banco Interamericano de Desarrollo, con la Secretaría General de la Integración Centroamericana, para la AECl, para la Dirección General de Política de Desarrollo, para distintos gobiernos latinoamericanos. Y no sólo eso, en unos días y como todos los años, algunos miembros de nuestro claustro continuarán sus labores docentes impartiendo clases en universidades del Salvador, Nicaragua o Cuba. ETEA decididamente coopera.

Esto es lo que hacemos. Y me he permitido contárselo a ustedes porque una institución sólo se define por lo que hace, pues sólo es si hace. Nosotros somos porque hacemos. Esto es lo que nos define.

Pero, además, y al mismo tiempo, lo que hacemos, lo hacemos, o al menos pretendemos hacerlo, de una forma especial. Y en esto, y no sólo en qué hacemos, es en lo que se debe notar que somos una obra de la Compañía de Jesús. 
ETEA, además, se caracteriza porque todo esto que hacemos (pensar, investigar, enseñar, publicar, colaborar y cooperar) pretendemos hacerlo bien. No sólo respetando escrupulosamente las leyes o cumpliendo determinadas normas éticas, sino intentando hacer cada día las cosas de una forma mejor, porque esa es la manera, llevada a nuestra actividad cotidiana, del "magis" de Ignacio de Loyola. Como se recoge en el decreto de conclusión de la 34 Congregación General, sobre las "características del modo de proceder", "el magis no es simplemente una más de la lista de características del jesuita. Las impregna todas. La vida entera de Ignacio fue la búsqueda de un peregrino hacia el magis, la siempre mayor gloria de Dios, el siempre más cabal servicio a nuestro próiimo, el bien más universal, los medios apostólicos más efectivos. La mediocridad no tenía puesto en la cosmovisión de lgnacio". Más aún, "el jesuita no está nunca satisfecho con lo establecido, lo conocido, lo probado, lo ya existente... Para nosotros, las fronteras y los límites no son obstáculos o términos, sino nuevos desafíos que encarar, nuevas oportunidades por las que alegrarse. En efecto, lo nuestro es una santa audacia, "una cierta agresividad apostólica", típica de nuestro modo de proceder".(p. 438).

Esto significa que hay una forma ETEA, adaptación de la manera de la Compañía, de hacer las cosas en nuestro determinado contexto, de cumplir con nuestras obligaciones, que hay un conjunto de valores que laten en lo que hacemos y en cómo lo hacemos y que no somos, porque no podemos serlo, neutrales. ETEA es un Centro de la Compañía de Jesús y encarna en sus objetivos, en su acción y en la forma de hacer, los valores de la Compañía, que son los valores de la Iglesia. $Y$ estos valores nacen, y así queremos proclamarlo, de la fe.

Pero, además, y con esto termino de explicar qué somos, ETEA es un centro adscrito a la Universidad de Córdoba, en la que llevamos ya treinta años y en la que estaremos, con la misma fidelidad y lealtad, hasta que sea realidad esa otra universidad, la Fernando III que, a instancias nuestras y de la Fundación San Pablo de Andalucía, el Parlamento andaluz autorizó en marzo del pasado año. Un nuevo marco jurídico para la vieja realidad que es ETEA.

No iniciamos, allá por 2001, el proceso que llevó a la constitución de la Universidad Fernando III, de la que me cabe el honor de ser patrono, porque no estuviéramos bien en la que ha sido también nuestra casa durante tanto tiempo, sino porque, por nuestra propia naturaleza y por la de los acontecimientos, no podíamos sentirnos ni ser iguales a los centros que son propios de la Universidad de Córdoba. Hemos sido y somos parte de la Universidad de Córdoba, podríamos decir que huéspedes en una gran casa común a la que estamos agradecidos por la hospitalidad que se nos ha dado y se nos da, pero unos y otros hemos de reconocer que, a pesar 
de los esfuerzos de todos, de lo mucho que tenemos en común y de la exquisitez y amistad con la que hemos sido y somos tratados, no somos más que huéspedes de la Universidad de Córdoba. Cuando llegue el momento de nuestra partida, algo dejaremos de nuestra historia atrás, pero viviremos tan cerca unos de otros, que la colaboración y los lazos que ahora nos unen permanecerán inalterados para mejor servir a la sociedad cordobesa y andaluza.

Esto que he contado es lo que somos. Esto es lo que hemos conseguido todos los que hemos trabajado en esta Casa. Esto es lo que refleja nuestra historia. Porque ETEA es un centro universitario de la Compañía de Jesús que es fruto del sueño de unos pocos y del desarrollo de una hermosa historia. Una historia hecha con el esfuerzo y la inteligencia de personas como Loring, Theotonio, Rodero, López Caballero, Sneesby, Summers, Porras, Cabanes, Romero, Paniagua, Jiménez, Muñizz, y de tantos otros de los que hoy somos herederos. Una hermosa historia de la que podemos estar legítimamente orgullosos. Una hermosa historia que nos exige más y más lejos, porque la recibimos en herencia.

\section{Nuestro futuro como responsabilidad}

Pero siendo esto importante, no es lo importante hoy, ni lo más importante. Porque lo importante es que ETEA tiene un hermoso futuro. Un futuro que es exigencia de nuestro propio pasado. Un futuro que también viene cargado de sueños. Un futuro que percibimos como los valientes de Víctor Hugo, como una oportunidad. Un futuro que hemos de construir con nuestro esfuerzo, día a día, y que ha de ser evolución, por adaptación al signo de los tiempos, de lo que hoy somos. Un futuro del que somos responsables.

Decía el Padre Kolvenbach en su discurso de febrero de 1994 que ETEA tiene un rasgo que quizás nosotros, desde dentro, no apreciemos tan fácilmente en el día a día de nuestro trabajo. Este rasgo es el "alto grado de fe en sí misma que la Institución ha mostrado a lo largo de su historia". Una confianza en sí misma que la ha hecho ir ganando poco a poco sus futuros.

Para ganar el futuro es fundamental que nos fijemos metas. Y metas por las que luchar con alegría porque, alcanzándolas, hacemos mejor lo que tenemos que hacer.

Una primera meta es la adaptación completa de la pedagogía y didáctica de la Casa a las exigencias del Espacio Europeo de Educación Superior, a lo que se ha dado en llamar el proceso de Bolonia. No es, para nosotros, una revolución, 
porque muchos de los presupuestos en los que se basa Bolonia ya están contenidos en la Ratio Studiorum de la Compañía (de ahí que no sea casualidad que uno de los centros líderes del proceso sea la Universidad de Deusto) y, con diverso grado, ya los venimos aplicando en esta Casa desde su origen. Así, el trabajo en grupo, las clases participativas, las prácticas o las tutorías son algo común para nosotros. Sin embargo, hemos de adaptar todos los programas, compararlos con los de las mejores universidades, extender la coordinación del sistema, jerarquizar los objetivos, ampliar la formación humanística, en una palabra, mejorar lo que hacemos, persiguiendo la calidad total en la docencia de tal forma que logremos la formación integral de las personas que se nos confían. Para ello buscaremos la acreditación de las titulaciones y de los procesos, mediante evaluaciones internas y externas. E incluso iremos más allá, estableciendo cartas de compromiso y exigencia entre los actores del proceso de enseñanza-aprendizaje. De igual forma, y como consecuencia también del proceso en el que vive la Universidad española, desarrollaremos nuevas titulaciones tanto de grado como de postgrado que respondan a las demandas que la sociedad constantemente hace.

Nuestros objetivos en el campo de la investigación son, si cabe, más ambiciosos. Hemos de potenciar los grupos de investigación ya constituidos y tradicionales de nuestra Casa, al tiempo que organizaremos grupos nuevos que nos permitan hacer aportaciones significativas en otros campos del pensamiento. Así, a los campos del desarrollo rural, la economía del desarrollo y la cooperación, la economía social, la ética empresarial o la responsabilidad social corporativa, hemos de sumar nuevas líneas de investigación en métodos cuantitativos y economía computacional, creatividad e innovación, emprendedores, banca y finanzas, derecho de empresa, etc. Todo ello en pos de crear pensamiento significativo y reconocido. Un reconocimiento que ha de pasar por la acreditación de la inmensa mayoría del claustro de la Casa.

Hemos de seguir también presentes en nuestro entorno mejorando la colaboración con todos. Así hemos de profundizar en el fomento de la iniciativa empresarial en el seno de nuestra Facultad, pues, como respondió un antiguo alumno a la pregunta de por qué inició su aventura empresarial, "si los de empresariales no crean empresas, ¿̇quién creará empresas para los de empresariales?". Y, más allá de la colaboración en la creación de empresas, estaremos en permanente contacto con las empresas ya existentes y otras instituciones como ONG, siempre prestos a servirles la formación que nos demanden y colaborar en todo lo que se nos pida. 
De igual forma, queremos ampliar el campo de nuestras colaboraciones con las administraciones públicas, en las que también destacan no pocos antiguos alumnos y alumnas, y a las que nos brindamos para ayudar en un mejor y mayor servicio de la sociedad.

Y en absoluto podemos dejar de colaborar, antes bien, hemos de profundizar, en el trabajo compartido con la Iglesia cordobesa de la que somos parte y con la que encontramos claros puntos de unión en la pastoral juvenil y universitaria para aportar nuestro grano de arena en su crecimiento.

Por su parte, la Fundación ETEA para el Desarrollo será el vehículo de la cooperación de ETEA con los más desfavorecidos. Esta Fundación ya tiene una entidad y capacidad que la hacen cada vez menos dependiente de su casa matriz, por lo que las relaciones entre las dos Instituciones tienen que entrar en una nueva fase.

En cuanto a las relaciones con otras universidades y centros de investigación queremos, en un primer momento, hacer un esfuerzo por profundizar los lazos y los intercambios con centros de la Compañía de Jesús, para formar con ellos una red de más densidad que la que ahora tenemos. Deusto, Comillas, ESADE, IQS, etc. así como Georgetown, Fordham, San Luis serán, Dios mediante, nuestras contrapartes para intercambiar alumnos, profesores y experiencias, para formar grupos de investigación, para trabajar en titulaciones conjuntas. Somos parte de una red de más de 180 instituciones universitarias por todo el mundo en la que "ninguna de ellas puede considerarse aislada y como abandonada a sí misma, sino que deben considerarse conectadas con todas las demás y solidarias con su suerte" (P. Kolvenbach, 22 de febrero, 1994).

ETEA quiere ser como una Casa abierta. Un lugar de encuentro entre distintas instituciones, cercanas y lejanas, un lugar de diálogo empresarial, social, universitario, cultural, político, religioso. Una Casa abierta a todos, a los antiguos alumnos y alumnas, a los empresarios y sindicatos, a las ONG, a los universitarios y a los que no lo son, a los creyentes y a los descreídos, a los de derechas y a los de izquierda. ETEA quiere seguir siendo algo que fue en sus orígenes: un lugar de encuentro. Pero también quiere ser parte de la conciencia crítica de nuestra sociedad y nuestro mundo porque tenemos ideas que dialogar y valores que aportar.

Todo esto, que sólo es la evolución, la adaptación, de este organismo vivo que es ETEA a los nuevos tiempos, lo queremos hacer persiguiendo el "magis", el más. Porque el "magis" es nuestra brújula. 
No lo vamos a hacer sólo porque sea lo que tenemos que hacer como universitarios, pues cualquier rector, director o decano estoy seguro que suscribiría mis palabras. No, lo vamos a hacer porque lo que tenemos que hacer brota de la voluntad de la Compañía de estar en las "fronteras de saberes y culturas", porque desde sus orígenes, la Compañía de Jesús ha considerado el compromiso en el trabajo intelectual como una dimensión propia de su misión recibida de la Iglesia y del sucesor de Pedro. Esta larga y notable tradición es universalmente conocida y se ha prolongado hasta nosotros. Al inscribirnos hoy en esta tradición, deseamos vivirla como una exigencia y una responsabilidad para el cuerpo entero de la Compañía, en todas nuestras misiones actuales'.

Se ratifica así, con hechos, el mandato, del Papa Benedicto XVI en su primer discurso a los miembros de la Congregación General, tras la elección del Padre Adolfo de Nicolás como nuevo general. En este discurso, el Papa pide que "la búsqueda de la calidad y la solidez humana, espiritual y cultural, debe caracterizar también a toda la múltiple actividad formativa y educativa de los jesuitas a favor de los más diversos tipos de personas, dondequiera que se encuentren". Todo ello velando "para que las obras e instituciones conserven siempre una identidad clara y explícita".

Estos retos exigirán de todos y cada uno de aquellos que componemos la plantilla de ETEA esfuerzo y sacrificio, generosidad y disponibilidad, inteligencia y estudio, exigencia y responsabilidad, identificación con la misión y con nuestra historia.

Nosotros, ETEA, una obra de la Compañía vamos a hacer todo lo que tenemos que hacer, lo mejor posible, con exigencia y con entusiasmo porque es nuestra vocación a la que somos llamados, porque es nuestra obligación como universitarios, porque es nuestro deber como parte de una Institución de la Compañía de Jesús.

\section{Coda final}

Permítanme que vaya terminando. Este es mi primer discurso público como $\mathrm{Di}$ rector de la Institución que nos acoge. Hoy, para todos los que la componemos, empieza, esperemos que para bien, otra etapa. Una etapa en la que la respon-

' Cf. Congregación General 35, Decreto 3, n 39, III. 
sabilidad de todo lo que ocurra será, al final, mía. Porque yo asumo, desde este momento, todos los errores que se comentan y por los que, de antemano, pido perdón. Pero estoy seguro de que todos los que componemos la Casa acertaremos más veces de las que erremos.

A mí sólo me queda pedir, además de a todos ustedes, ayuda a la Providencia para que se me cumpla el deseo de que, cuando llegue el momento de pasar el testigo de esta responsabilidad a aquel o aquella que me sustituya, pueda pronunciar las mismas palabras que Galdós pone en boca de Nelson en Trafalgar: "Bendito sea Dios, he cumplido con mi deber".

Muchas gracias. 